\title{
A atuação do Tribunal de Contas na implementação de políticas públicas
}

\author{
The performance of the Court of Auditors on the implementation \\ of public policies
}

\author{
Tiago Cappi Janini ${ }^{1}$ \\ Mário Augusto Quinteiro Celegatto ${ }^{2}$
}

\begin{abstract}
Resumo: Um dos grandes problemas que envolve o direito atualmente refere-se à concretização dos direitos fundamentais. As políticas públicas, vistas como programas de governo para efetivar os direitos sociais, requerem uma efetiva implementação. Todavia, o Poder Executivo encontra diversos obstáculos nesse percurso, principalmente no que diz respeito ao uso do dinheiro público. Diante disso, surge a problemática: o Tribunal de Contas pode interferir nas decisões administrativas que estabelecem políticas públicas? O presente trabalho tem, portanto, a pretensão de demonstrar como se afiguram as políticas públicas dentro da sociedade democrática de direito, esclarecendo qual a relação guardada pelo Tribunal de Contas com a implementação de tais medidas. Nesse sentido, este artigo buscará demonstrar a hipótese de que o Tribunal de Contas tem à sua disposição diversos instrumentos jurídicos que garantem uma fiscalização efetiva na implementação de políticas públicas, especialmente a auditoria operacional. Utilizando-se do método dedutivo, chega-se à conclusão que o Tribunal de Contas é um importante ator na efetivação de políticas públicas, devendo acompanhar a sua criação e implementação junto ao Poder Executivo.
\end{abstract}

Palavras-chave: Efetivação dos direitos sociais. Políticas Públicas. Tribunal de Contas. Auditoria operacional.

Abstract: One of the major problems involving the law currently refers to the implementation of fundamental rights. The public policy, seen as government programs to effect social rights, require an effective implementation. However, the Executive Power find a several obstacles on this course, especially regarding the use of public money. At that, there is the problem of identifying whether the Court of Auditors can interfere in the administrative decisions that establish public policies? This paper has the claim to demonstrate how the public policies works within the democratic society of law, clarifying the relationship between the Court of

\footnotetext{
1 Doutorado em Direito pela Pontifícia Universidade Católica de São Paulo. Professor da Universidade Estadual do Norte do Paraná.

${ }^{2}$ Especialização em Direito Processual Civil - Pós-graduação L. Sensu pela Universidade Anhanguera - Uniderp, Brasil. Professor de Direito Processual Civil, Direito do Consumidor e Direito Civil, Membro da ABDPro Associação Brasileira de Direito Processual, Professor da EMAP - Escola da Magistratura do Paraná
} 
Auditors and the implementation of the public policies. In this sense, this article will demonstrate that the Court of Auditors has at your disposal various legal instruments that ensure an effective supervision on the implementation of public policies, especially the operational audit. Using the deductive method, this paper concludes that the Court of Auditors is an important actor in the implementation of public policies, and should accompany your creation and implementation by the Executive Power.

Keywords: Implementation of social rights. Public Policies. Court of Auditors. Operational audit.

\section{INTRODUÇÃO}

Um dos grandes problemas que envolve o direito atualmente refere-se à efetivação dos direitos fundamentais. Principalmente com a Constituição de 1988, após um período de ditadura e restrição de direitos os brasileiros viram positivados no texto constitucional um vasto rol de direitos fundamentais. Apesar dessa louvável iniciativa, nos dias de hoje o sistema jurídico envolve-se com a problemática de que não basta ter explícitos esses direitos, mas precisa concretizá-los; fazer com que os cidadãos os usufruam satisfatoriamente.

Para poder implementar as políticas públicas o Poder Executivo precisa de recursos financeiros obtidos, principalmente, por meio da cobrança de tributos. Porém, mesmo com a alta arrecadação tributária, o Poder Executivo não consegue implementar todas as políticas públicas essenciais para que os direitos fundamentais consigam ser efetivados. Diante disso, este trabalho tem como problemática identificar qual a importância da participação do Tribunal de Contas na fiscalização do uso do dinheiro público para a concretização de direitos fundamentais por meio da realização de políticas públicas. Nesse sentido, surge a questão: a Corte de Contas pode interferir nas decisões administrativas que estabelecem políticas públicas? O presente artigo tem, portanto, a pretensão de demonstrar como se afiguram as políticas públicas dentro da sociedade democrática de direito, esclarecendo qual a relação guardada pelo Tribunal de Contas com a implementação de tais medidas.

Nesse sentido, este artigo buscará demonstrar a hipótese de que o Tribunal de Contas tem à sua disposição diversos instrumentos jurídicos que garantem uma fiscalização efetiva na implementação de políticas públicas, especialmente a auditoria operacional, sendo competente para fiscalizar e punir os gestores públicos que façam mal uso do dinheiro público comprometendo a concretização dos direitos fundamentais com a implementação de políticas 
públicas, e tem como objetivos gerais identificar o conceito de políticas públicas, os óbices alegados pelo Poder Executivo para implementar políticas públicas, o regime jurídico do Tribunal de Contas, e, por fim, demonstrar os desdobramentos da atuação do Tribunal de Contas na efetivação das políticas públicas.

Preocupado em evidenciar que o Tribunal de Contas é um órgão indispensável para a concretização do Estado Democrático de Direito, este estudo será desenvolvido por meio da aplicação do método dedutivo, sustentando-se na percepção derivada de rigoroso exame da Constituição da República Federativa do Brasil, da vasta legislação vigente em nosso país, da doutrina, entre outros meios de informações jurídicas e fáticas relevantes.

\section{AS POLÍTICAS PÚBLICAS E A CONCRETIZAÇÃO DO ESTADO DEMOCRÁTICO DE DIREITO}

O Estado Democrático de Direito da maneira como é conhecido hoje decorreu de um extenso processo de evolução da forma como as sociedades foram se organizando ao longo dos séculos. A imensa dificuldade em se chegar a uma definição unívoca para "democracia" deriva dessa sua variação conforme os tempos e os povos. Trata-se, como prefere José Afonso da Silva (1998, p. 129), de um conceito histórico, que envolve a sociedade, evoluindo em suas garantias e direitos e assegurando uma maior participação popular nas escolhas do Estado.

Um dos eixos institucionais do ideal democrático moderno, ao lado da representação e da soberania do povo, é a arquitetura de uma Constituição. Nesse sentido, as palavras de Paulo Bonavides (2015, p. 347-8): "Nas formas democráticas a Constituição é tudo: fundamento do direito, ergue-se perante a Sociedade e o Estado como o valor mais alto, porquanto de sua observância deriva o exercício permanente da autoridade legítima e consentida". A democracia deve ser vista conforme a forma e medida apontadas nos textos constitucionais. Nesse caso, com base nas lições de J. J. Gomes Canotilho (2014, p. 287 e seguintes), o princípio democrático é uma norma jurídica constitucional com dimensões materiais e procedimentais. Em termos substanciais, condiciona o domínio político à busca de determinados fins e à realização de certos valores e princípios. Sob o aspecto procedimental, a democracia vincula a legitimação do poder à observância de regras e processos.

Para se ter um Estado Democrático, não basta o texto constitucional trazer as regras e procedimentos referentes à participação popular, seja para eleger seus representantes, seja para atuar de modo mais direto nas escolhas políticas. O conteúdo dos atos dos representantes 
também deve convergir com os desejos e necessidades do povo que o elegeu. Além de ser eleito segundo as regras constitucionalmente previstas, o representante tem de agir na persecução dos fins e valores exaltados no texto constitucional. Desse modo, em sentido mais moderno, visando emergir o aspecto substancial da democracia, incorpora-se na sua definição a afirmação dos direitos fundamentais do ser humano. "A democracia é, em certo sentido, o regime político natural dos direitos fundamentais, o único que proporciona as condições mínimas de realização da liberdade, da igualdade e da fraternidade" (MACHADO; VOLANTE; VIANA; 2016, p. 162). Assim, o Estado Constitucional Democrático se traduz em um Estado garantidor, legitimador de direitos, não somente positivista.

Com a inclusão dos direitos fundamentais na definição de um Estado Democrático de Direito, não basta apenas o seu aspecto formal. Deve-se buscar, por meio do Estado, a efetivação desses direitos, com a implementação de políticas públicas, afirmando os fins e valores positivados no texto constitucional.

A expressão "políticas públicas”, segundo Eros Roberto Grau (2008, p. 25), designa a atuação do Estado, desde a pressuposição de uma bem marcada separação entre Estado e sociedade. Já Yuri Lopes de Mello (2011, p. 11) as define como medidas positivadas por mio de planos e programas governamentais, como instrumentos a efetivação dos direitos declarados na Constituição Federal. Oswaldo Canela Júnior (2009, p. 17-18) conceitua política pública em um sentido mais amplo como:

[...] o conjunto de atividades do Estado tendentes a seus fins, de acordo com metas a serem atingidas. Trata-se de um conjunto de normas (Poder legislativo), atos (Poder Executivos) e decisões (Poder Judiciário que visam à realização dos fins primordiais do Estado).

A principal função das políticas públicas é proporcionar uma distribuição justa da receita obtida pelo governo, com vistas a erradicar, ou ao menos minimizar, a pobreza e a marginalização e reduzir as desigualdades sociais e regionais (art. $3^{\circ}$, III da CF). Um sistema tributário abusivo com distribuição não direcionada para a melhoria dos mais necessitados não condiz com um Estado democrático.

Desse modo, as políticas públicas podem ser compreendidas como um conjunto de programas, ações ou decisões adotadas pelo Estado com a participação, direta ou indireta, de entes públicos ou privados com o objetivo de assegurar direitos previstos na Constituição Federal, evitando-se as formas de exclusão social. Portanto, a adoção de políticas públicas é imprescindível para a efetivação do Estado Democrático de Direito.

Todavia, para a implementação das políticas públicas é necessário que o Estado tenha 
recursos financeiros, que advém, principalmente da arrecadação de tributos. É nesse cenário que se destaca a importância do Tribunal de Contas como órgão fiscalizador do uso do dinheiro público, proporcionando sua aplicação eficiente direcionada à concretização dos direitos sociais com vistas a reduzir as desigualdades sociais.

\section{OBSTÁCULOS À IMPLEMENTAÇÃO DE POLÍTICAS PÚBLICAS}

O legislador constitucional, ao elaborar a Carta Cidadã de 1988, instituiu um Estado Democrático Direito, destinado a assegurar, dentre outros, o exercício dos direitos sociais e individuais, a liberdade, a segurança, o bem-estar, o desenvolvimento, a igualdade e a justiça. Percebe-se que o objetivo da Carta Constitucional é garantir uma vida digna, promovendo a integração social.

Todavia, para que a dignidade da pessoa humana seja efetivamente assegurada, existe a necessidade de implementação de políticas públicas destinadas a concretizar os direitos sociais. As políticas públicas, como acima mencionado, são medidas positivadas por meio de planos e programas governamentais; verdadeiros instrumentos para a efetivação dos direitos declarados na Constituição Federal. É por meio das políticas públicas que a sociedade pode ver os direitos fundamentais concretizados.

Contudo, implementar e desenvolver políticas públicas não é tão simples como se apresenta. Surgem obstáculos a serem enfrentados: separação dos Poderes no que diz respeito à judicialização das políticas públicas, a escassez orçamentária e a reserva do possível.

Diante da ineficiência do Poder Executivo em concretizar os direitos fundamentais dos cidadãos, há uma corrida ao Judiciário para que dê efetividade às garantias constitucionais. Sobre o tema, Guilherme Fonseca de Oliveira e Fernando de Brito Alves (2014, p. 08) aduzem que "o ativismo se sustenta à medida que - e somente se - o processo político falha na tutela de direitos fundamentais - notadamente no caso das minorias em razão de sua baixa participação nesse processo”. Dessa forma, tem-se no Judiciário papel indispensável para a tutela à dignidade da pessoa humana, garantindo ao ser humano o que lhe é de direito, naquilo que lhe esteja ao alcance, por meio de determinações direcionadas ao Poder Executivo, que de pronto atendimento não exerceu as ações que dele se espera. Todavia, essa atuação do Poder Judiciário se reflete na distribuição dos recursos públicos dentro do orçamento, implicando em remanejamento de verbas pelo Poder Executivo. Ademais, o Supremo Tribunal Federal vem consolidando o entendimento no sentido que o Poder Judiciário deve intervir nas 
políticas públicas com vistas a concretizar o direito à saúde, com supedâneo nos artigos $6^{\circ} \mathrm{e}$ 196 da Carta Magna, no núcleo básico constitucional que qualifica o mínimo existencial e das legislações ordinárias em consonância com a reserva do possível (RUSSO; LEHFELD, 2016, p. 12).

Com a massificação dos direitos sociais pela Constituição Federal de 1988, muitas vezes o orçamento público é insuficiente para assegurar a todos o usufruto digno desses direitos. A escassez de recursos é um desafio a ser enfrentado pelo Poder Público para implementar as políticas públicas. Nesse contexto, surge a teoria da reserva do possível. Desse modo, a prestação proclamada deve corresponder ao que o indivíduo pode razoavelmente exigir da sociedade, de tal sorte que, mesmo em dispondo o Estado de recursos e tendo poder de disposição, não se pode falar em uma obrigação de prestar algo que não se mantenha nos limites do razoável. Há, em contrapartida, conflito de interesses, na maioria das vezes, como na hipótese de o pleito tratar apenas um indivíduo e os recursos da administração pública deveriam ter outra destinação que atendesse ao interesse coletivo. Por tais razões, é inescusável a aplicação do princípio da razoabilidade na decisão judicial.

Tal teoria, entretanto, não deve ser utilizada como barreira para a não realização dos direitos fundamentais. Por assim dizer, Kátia Cristine Santos de Oliveira e Jamille Coutinho Costa, enfatizam (2011, p. 08):

\begin{abstract}
A teoria da reserva do possível tem sido interpretada como limitação à efetivação de Direitos Fundamentais Sociais em face da incapacidade jurídica do Estado em dispor de recursos para a efetivação do Direito. Essa teoria não pode servir como barreira para a não realização dos Direitos e prestações sociais. Ela não pode ser usada como desculpa para omissão Estatal no campo da efetivação dos Direitos Fundamentais Sociais. Infere-se, com isso, que não se pode negar a prestação do Direito à Saúde/Vida sob o argumento da indisponibilidade de recursos.
\end{abstract}

Não bastasse esse discurso, aliou-se tal argumento à justificativa de garantia do mínimo existencial. Sobre esse assunto, ensina Ricardo Lobo Torres (2011, p. 69):

O mínimo existencial não tem conteúdo específico. Abrange qualquer direito, ainda que originalmente não-fundamental (direito à saúde, à alimentação etc.), considerado em sua dimensão essencial e inalienável. Sem o mínimo necessário à existência cessa a possibilidade de sobrevivência do homem e desaparecem as condições iniciais de liberdade. A dignidade humana e as condições materiais da existência não podem retroceder aquém de um mínimo, do qual nem os prisioneiros, os doentes mentais e os indigentes podem ser privados. O fundamento do direito ao mínimo existencial, por conseguinte, reside nas condições para o exercício da liberdade, que alguns autores incluem na liberdade real, na liberdade positiva ou até na liberdade para ao fito de diferença-las da liberdade que é mera ausência de constrição.

Dessa forma, diante da negativa do Estado em cumprir o plano constitucional, 
valendo-se das teses da reserva do possível e do mínimo existencial, em muitas das situações, é possível perceber que a concretização das políticas públicas depende de incentivos, cobranças e fiscalizações à sua efetivação.

Com isso, mostram-se as digressões feitas por Celso de Mello, Ministro do Supremo Tribunal Federal:

\begin{abstract}
A cláusula da reserva do possível - que não pode ser invocada, pelo Poder Público, com o propósito de fraudar, de frustrar e de inviabilizar a implementação de políticas públicas definidas na própria Constituição - encontra insuperável limitação na garantia constitucional do mínimo existencial, que representa, no contexto de nosso ordenamento positivo, emanação direta do postulado da essencial dignidade da pessoa humana. (...) A noção de "mínimo existencial", que resulta, por implicitude, de determinados preceitos constitucionais (CF, art. $1^{\circ}$, III, e art. $3^{\circ}$, III), compreende um complexo de prerrogativas cuja concretização revela-se capaz de garantir condições adequadas de existência digna, em ordem a assegurar, à pessoa, acesso efetivo ao direito geral de liberdade e, também, a prestações positivas originárias do Estado, viabilizadoras da plena fruição de direitos sociais básicos, tais como o direito à educação, o direito à proteção integral da criança e do adolescente, o direito à saúde, o direito à assistência social, o direito à moradia, o direito à alimentação e o direito à segurança. Declaração Universal dos Direitos da Pessoa Humana, de 1948 (Artigo XXV). [ARE 639.337 AgR, rel. min. Celso de Mello, j. 23-8-2011, $2^{\mathrm{a}}$ T, DJE de 15-9-2011.]
\end{abstract}

Evidencia-se que uso indiscriminado do argumento da reserva do possível deve ser evitado, a fim de que os direitos fundamentais sociais sejam efetivados por meio da realização de políticas públicas e, por consequência, seja assegurado ao cidadão o mínimo existencial.

A execução das políticas públicas sofre, portanto, a influência de diversos fatores que condicionam seu sucesso ou fracasso. Nesse ponto é que se reconhece a real importância da atuação do Tribunal de Contas na efetivação das medidas propostas, da forma delineada pelos princípios constitucionais pelos quais se deve guiar o Estado, principalmente na análise dos gastos públicos. Para fins deste estudo importa sobretudo a forma como o Poder Público utiliza o dinheiro público na efetivação dessas medidas, que deve ser rigidamente controlado pelo Tribunal de Contas.

\title{
3 CONSIDERAÇÕES ACERCA DO TRIBUNAL DE CONTAS
}

Os atos praticados pela Administração Pública estão sujeitos a um controle, que pode ser interno ou externo. O controle interno é efetuado por órgãos da própria Administração Pública. Por outro lado, o controle externo é exercido por órgãos alheios à Administração Pública, que compreende o controle parlamentar direto, o controle exercido pelo Tribunal de Contas e o controle jurisdicional.

Diante dessas possibilidades, importa destacar o controle efetuado pelo Tribunal de 
Contas, que auxilia o Congresso Nacional a realizar um controle da Administração Pública de maneira sistemática e minuciosa.

O Tribunal de Contas da União (TCU) é um órgão com regime jurídico definido constitucionalmente, o que demonstra sua inegável importância dentro do sistema jurídico nacional, apesar de ser pouco conhecido pela sociedade em geral. Tem como função principal auxiliar o Congresso Nacional no controle financeiro externo da Administração Pública.

Por meio de nota institucional, o Tribunal de Contas da União (ON LINE) explica que:

O TCU é o órgão de controle externo do governo federal e auxilia o Congresso Nacional na missão de acompanhar a execução orçamentária e financeira do país e contribuir com o aperfeiçoamento da Administração Pública em benefício da sociedade. Para isso, tem como meta ser referência na promoção de uma Administração Pública efetiva, ética, ágil e responsável.

O Tribunal é responsável pela fiscalização contábil, financeira, orçamentária, operacional e patrimonial dos órgãos e entidades públicas do país quanto à legalidade, legitimidade e economicidade.

A regulamentação constitucional do TCU lhe garante autonomia, porquanto possui um quadro próprio de pessoal (art. 73), Ministros com as mesmas garantias, prerrogativas, impedimentos, vencimentos e vantagens dos Ministros do Superior Tribunal de Justiça (art. $\left.73, \S 3^{\circ}\right)$ e lei própria de auto-organização. Caio Tácito (2005, p. 216) enfatiza que "a autonomia dos Tribunais, para o êxito de suas funções constitucionais, impõe sujeição a dois pressupostos essenciais: o da independência do órgão e o das prerrogativas de seus membros".

O TCU é integrado por nove Ministros, cujos requisitos para investidura são: (i) brasileiros com mais de 35 anos e menos de 65 anos de idade, (ii) idoneidade moral e reputação ilibada; (iii) dispor de notórios conhecimentos jurídicos ou contábeis, econômicos, financeiros ou de administração pública; (iv) contar com mais de dez anos de exercício de função ou efetiva atividade profissional exigente da espécie de conhecimento referidos (art. $73, \S 1^{\circ}$ ). Um terço dos Ministros do TCU é nomeado pelo Presidente da República, após aprovação do Senado Federal, sendo dois alternadamente dentre auditores e membros do Ministério Público junto ao Tribunal, indicados em lista tríplice pelo Tribunal, segundo os critérios de antiguidade e merecimento. Os demais dois terços são escolhidos pelos Congresso Nacional (art. 73, $\S 2^{\circ}$ ). Importa consignar que seus membros possuem status de Ministros, com as prerrogativas atribuídas à Magistratura (art. 73, § $3^{\circ}$ ), assegurando-lhes maior autonomia em suas decisões, já que possuem vitaliciedade e são julgados pelo Supremo Tribunal Federal nas infrações penais comuns e nos crimes de responsabilidade (art. 102, I, c). Ademais, o TCU tem iniciativa para apresentar projeto de lei visando a dispor sobre a 
sua organização administrativa, criação de cargos, remuneração de servidores e fixação de subsídios dos membros da Corte. $\mathrm{O}$ art. 73 combinado com o art. 96 da Constituição permite à Corte de Contas eleger seus órgãos diretivos e elaborar seus regimentos internos, com observância das normas de processo e das garantias processuais das partes. Valendo-se dessa competência outorgada pelo texto constitucional, foi publicada a Lei $n^{\circ}$ 8.443/92, a Lei Orgânica do Tribunal de Contas da União e há ainda o Regimento Interno do Tribunal de Contas da União, diplomas normativos que visam organizar a sua atividade.

Com isso, apesar de auxiliar o Poder Legislativo, o TCU não o integra como bem explica Bernardo Gonçalves Fernandes (2017, p. 1037, grifos do original):

Certo é que, embora auxilie o Poder Legislativo, ele não integra o Poder Legislativo nem mesmo é subordinado a ele (aqui temos uma relação de cooperação e não de subordinação), mantendo apenas um vínculo institucional por disposição eminentemente constitucional. Portanto, o TCU é um órgão autônomo e independente. É mister ainda salientar que ele goza das mesmas garantias institucionais do Poder Judiciário, exercendo, no que couber, as atribuições previstas no art. 96 da CR/88 (artigo que diz respeito à autonomia administrativa e ao autogoverno dos Tribunais do Poder Judiciário).

Na verdade, o Tribunal de Contas não integra nenhum dos três Poderes. É um órgão institucional autônomo. Apesar do nome, o Tribunal de Contas não exerce função jurisdicional, mas sim administrativa (CRETELLA JR, 1986, p. 13), com a fiscalização das contas públicas. Essas considerações ressaltam a autonomia dos Tribunais de Contas em relação aos demais Poderes da República. Nas palavras de Caio Tácito (2005, p. 216, grifo do original): "O auxílio do Tribunal de Contas ao controle externo afeto ao Congresso Nacional (art. 71 da Constituição Federal) não configura vínculo de subordinação ou relação de hierarquia".

Além do TCU, cada Estado da federação conta com um Tribunal de Contas em seu âmbito. O sistema constitucional do TCU aplica-se, no que couber, à organização, composição e fiscalização incumbentes aos Tribunais de Contas dos Estados e do Distrito Federal, bem como aos Tribunais e Conselhos de Contas dos Municípios (art. 75 da Constituição Federal). Bem lembra Jair Lins Netto (1995, p. 77) que não existe vinculação hierárquica de qualquer espécie entre o Tribunal de Contas da União e os Tribunais de Contas dos Estados e dos Municípios; cada qual exerce as competências que lhes são traçadas pelo sistema jurídico.

A título de exemplo, vale ressaltar a definição institucional apresentada pelo Tribunal de Contas do Estado do Paraná (ON LINE): 


\begin{abstract}
A propósito, você sabe o que o TCE faz? Ele é o órgão responsável pela fiscalização do uso do dinheiro público, do Estado e dos 399 Municípios paranaenses, em complemento à atividade fiscalizadora do Poder Legislativo (Assembleia Legislativa e Câmaras de Vereadores). Além de controlar todo volume de dinheiro público investido pelo governo do Paraná e prefeituras, o TCE também informa à comunidade o resultado destas contas públicas, isto é, se o dinheiro público foi aplicado corretamente e se os serviços oferecidos à população têm qualidade.
\end{abstract}

Já com relação aos Tribunais de Contas Municipais, a Constituição Federal de 1988 expressamente, no $\S 4^{\circ}$ do art. 31 , vedou a sua criação ou de outros órgãos de contas municipais. Os Tribunais de Contas Municipais existentes na época da promulgação do texto constitucional permanecem, não precisaram ser extintos. Os municípios em que não existe o órgão fiscalizador municipal são fiscalizados externamente pelo Poder Legislativo Municipal com o auxílio dos Tribunais de Contas do respectivo Estado. Assim, os Tribunais de Contas Estaduais, além de fiscalizarem o gasto do dinheiro público estadual, igualmente auxiliam as Câmaras Municipais no controle externo feito junto aos municípios.

Desse modo, como o Tribunal de Contas é detentor de garantias de autonomia funcional, administrativa e financeira, comuns inclusive a dos demais Tribunais do Judiciário, foram-lhe outorgadas competências para proteção dos direitos fundamentais dos cidadãos.

\title{
4 ATRIBUIÇÕES DO TRIBUNAL DE CONTAS E A IMPLEMENTAÇÃO DE POLÍTICAS PÚBLICAS
}

Como se observou, as políticas públicas são diretrizes para a distribuição de recursos públicos em investimentos que beneficiem a sociedade, de modo a garantir o mínimo necessário para que se tenha uma vida digna. Essas decisões tomadas pelo Poder Público se refletem no exercício de um serviço público. O governo, todavia, ao prestar efetivamente qualquer atividade administrativa tem de pautar essa sua decisão nos textos jurídicos, levando em consideração, principalmente, os princípios constitucionais, demonstrando suas escolhas, os meios de execução dessa atividade e os gastos realizados.

Por outro lado, a implementação de políticas públicas enfrenta alguns obstáculos, principalmente relacionados ao dinheiro disponível nos cofres públicos para fazer frente aos seus gastos. Entretanto, é amplamente noticiado o despreparo do Estado brasileiro para formular e executar políticas de desenvolvimento sustentável, assegurando a dignidade de seus cidadãos. Mesmo com crescentes aumentos na arrecadação, setores como educação, saúde, moradia, trabalho e segurança são carentes, sempre tratados como prioridades pelos governantes, mas que nunca conseguem garantir condições mínimas de sua concretização 
para a população.

Nesse cenário, destaca-se a atuação do Tribunal de Contas como uma instituição constitucional cuja finalidade consiste em fiscalizar a aplicação do dinheiro público, ou seja, fiscalizar a concretização das políticas públicas. Como explica Ricardo Lobo Torres (1993, p. 33) há uma relação essencial e profunda entre os direitos fundamentais e as finanças públicas. A integridade e a defesa dos direitos fundamentais dependem do equilíbrio da atividade financeira do Estado. É que a garantia e concretização dos direitos fundamentais demandam o aporte de recursos públicos substanciais. Diante disso, o autor (TORRES, 1993, p. 35, grifo do original) ressalta a importância do Tribunal de Contas:

Cabendo ao Tribunal de Contas, de acordo com o art. 70 da Constituição Federal, a fiscalização contábil, financeira, orçamentária, operacional e patrimonial da União e das entidades da administração direta e indireta, quanto à legalidade, legitimidade e economicidade, segue-se que passa ele a exercer papel de suma importância no controle das garantias normativas ou principiológicas da liberdade, ou seja no controle da segurança dos direitos fundamentais.

Segundo Paulo Nogueira da Costa (2014, p. 489), o controle exercido pelos Tribunais de Contas é pautado no princípio constitucional da boa governança, imposto a todos os órgãos do Estado, devendo o mesmo, além de garantir a justiça financeira em favor do povo, prestar contas ao titular da soberania. $\mathrm{O}$ autor ainda defende a accountability como elemento central da boa governança estatal, que trata do dever de prestar contas por todos que exercem poderes públicos, dessa forma será possível tornar real a ideia de Estado responsável, dirimido pela boa governança, e que vem sendo reconhecido por várias instâncias internacionais.

O Tribunal de Contas, portanto, realiza o controle de legalidade, de legitimidade e de economicidade das contas públicas, além da aplicação das subvenções e renúncias de receitas, conforme o art. 70 da Constituição. Por meio do controle de legalidade, o órgão irá observar se a Administração Pública realizou as políticas públicas conforme os ditames legais. Há de se lembrar que esse controle deve ser feito em sentido amplo, não se esgotando na legalidade estrita, devendo-se estender-se às diretrizes constitucionais, especialmente no que diz respeito aos princípios.

Já o controle da economicidade, explica Ricardo Lobo Torres (1993, p. 36-7), é o "controle da eficiência na gestão financeira e na execução orçamentária, consubstanciada na minimização de custos e gastos públicos e na maximização da receita e da arrecadação". O Tribunal de Contas deve verificar o custo/benefício no fornecimento dos bens e serviços públicos destinados a garantir os direitos fundamentais, em uma harmonia entre receita e 
despesa de modo a não onerar demasiadamente o cidadão com o pagamento de tributos.

Assim sendo, verifica-se que o Tribunal de Contas é órgão autônomo, essencial para assegurar a justiça financeira em favor da população do ente federado a que esteja vinculado, porém, sua atuação possui limites importantes que devem ser respeitados para o bom funcionamento da sociedade. Desse modo, observa-se que o Tribunal de Contas é sobremodo importante na contribuição para a implementação de políticas públicas.

As políticas públicas derivam de uma decisão política tomada pela Administração Pública. Essas decisões devem estar em consonância com todo o sistema jurídico nacional, implementadas tendo em vistas a legalidade, a legitimidade e a economicidade de suas despesas, conforme determinada o art. 70 da Constituição Federal. Não observadas essas balizas na definição das políticas públicas, deve-se desencadear a interferência do controle externo na tentativa de retomada do iter constitucional, aplicando, inclusive, medidas punitivas.

Avaliar a discricionariedade administrativa não compete ao Tribunal de Contas, pois invadiria esfera do Poder Executivo. Todavia, isso não impõe restrição absoluta para fiscalizar as escolhas feitas pelo Poder Público que implicam em determinadas políticas públicas.

Como alerta Otávio Lessa (2013, p. 10 e seguintes) o regime jurídico constitucional das Cortes de Contas prevê diversos instrumentos jurídicos, como auditoria de gestão, auditoria operacional, termos de ajuste de gestão, inteligência de TI aplicada ao "negócio", acompanhamentos dos gastos mais relevantes do orçamento e ações estruturadoras, voltados para uma fiscalização fundamentada na efetividade do controle pelos resultados das políticas públicas.

Nesse contexto, a auditoria operacional realizada pela Corte de Contas é um importante instrumento para dar efetividade às políticas públicas. Sabrina Nunes Iocken (2013, p. 07 e seguintes) ao compreender o sistema das políticas públicas como uma série de atos multidisciplinares, muitas vezes incoerentes entre si, com atuação de diversos atores que gera imprevisibilidades no seu percurso de implementação, destaca o controle de resultados a cargo dos Tribunais de Contas pela via das auditorias operacionais. Explica a autora (IOCKEN, 2013, p. 08) que essa análise “compreende a avaliação do cumprimento dos programas e ações de governo e do desempenho das unidades e entidades jurisdicionadas ao tribunal de contas, no que se refere aos seus objetivos, metas e prioridades, bem como à alocação e uso de recursos disponíveis". 
As contingências a que se sujeitam as ações públicas precisam ser previamente compreendidas pelo Tribunal de Contas, que deve apontar os desvios na efetivação das políticas públicas para o que o Poder Público retome o seu curso. A avaliação promovida pelas auditorias tem por finalidade observar o gasto público a partir dos princípios da economicidade, eficiência, eficácia, efetividade e probidade. As deficiências apuradas pela Corte de Contas devem ser apontadas para a apresentação do Plano de Ação pelo Poder Público, constando a indicação dos responsáveis, das atividades e dos prazos para a implementação das recomendações e determinações formuladas. Após o Plano de Ação ser encaminhado pelo gestor e aprovado pelo órgão colegiado do tribunal, surge um compromisso entre ambos para o cumprimento das atividades acordadas. Por fim, o tribunal deve elaborar um relatório específico tratando do impacto da auditoria, indicando os benefícios alcançados (IOCKEN, 2013, p. 09).

A intervenção do controle externo na gestão pública tem de ser feita de forma equilibrada, atenta ao orçamento público e aos princípios da eficiência e da probidade administrativa, apresentando soluções com menor onerosidade possível. O Tribunal de Contas deve atuar, portanto, de modo proativo “(re)orientando e (re)alinhando a atividade administrativa na busca por resultados dos programas governamentais mais eficientes e pela qualidade do gasto público' (IOCKEN, 2013, p. 09).

Assim, a participação dos Tribunais de Conta na implementação das políticas públicas deve ser iniciada previamente e seguir todo o percurso de sua implementação. Não basta apenas que a corte observe o resultado final e sancione possíveis erros. A criação e a efetivação das políticas públicas devem ser acompanhadas de perto pelo Tribunal, realizando o seu controle externo, que pode resultar um grande desenvolvimento na gestão pública, além de proporcionar maior controle social e integração com demais órgãos públicos.

\section{CONSIDERAÇÕES FINAIS}

Um dos principais problemas enfrentados pelo direito e pela política é a efetivação dos direitos sociais. O vasto rol de direitos fundamentais constitucionalmente assegurados dificulta a sua concretização. Por outro lado, a ineficiência do Poder Executivo é elemento central nessa dificuldade. Nessa perspectiva, é importante buscar soluções no sistema jurídico que facilitem o efetivo uso desses direitos pelos cidadãos. O Tribunal de Contas torna-se, nesse contexto, um elemento de suma importância, pois fiscaliza o uso do dinheiro público, 
evitando desperdícios e impondo aos governantes uma atuação mais eficiente.

De forma mais específica, conclui-se que a atuação do Tribunal de Contas está direcionada a verificar a finalidade dada ao dinheiro público, acompanhando a execução orçamentária e financeira do país e contribuindo com o aperfeiçoamento da Administração Pública, direta e indireta, em benefício da sociedade, além de, quando necessário, exigir medidas assecuratórias ao cumprimento dos preceitos fundamentais.

O sistema constitucional prevê diversos instrumentos para que o Tribunal de Contas realize o controle externo das políticas públicas. A auditoria operacional é uma forma que pode ser feita a fiscalização desde a criação das políticas públicas, passando por sua fase de implementação. Não basta à Corte analisar o resultado final sancionando os desvios de conduta dos responsáveis. É preciso que exista uma visão gerencial e estratégica no controle das políticas públicas. É muito mais eficiente que o Tribunal de Contas aponte desvios no percurso de efetivação de uma política pública, que tenha tempo de ser corrigida, do que aplicação uma pesada multa ao órgão.

O Tribunal de Contas, portanto, exerce papel indispensável à democratização da sociedade, sendo órgão responsável por fiscalizar e exigir que se cumpram os preceitos fundamentais, verificando a finalidade dada ao dinheiro público. A atuação do tribunal não deve se restringir apenas à verificação se há desvio de bens e recursos público; deve ir além, observando parâmetros qualitativos das ações estatais e sua relação com os gastos públicos.

É evidente que além dessa auditoria efetuada pelo Tribunal de Contas, com caráter preventivo, o órgão possui a possibilidade de aplicar sanções quando observar qualquer desvio de conduta na prática de políticas públicos pelo Poder Público.

O que se observa é uma tímida atuação dos Tribunais de Contas no controle das políticas públicas, devendo voltar suas atenções não só no caráter repressivo, com vistas a aplicar sanções, mas também realizar um controle preventivo, durante todo o percurso de implementação das políticas públicas, de acordo com princípios da probidade, economicidade e eficiência do atuar administrativo, contribuinte para o fortalecimento do Estado Democrático de Direito.

\section{REFERÊNCIAS}

BONAVIDES, Paulo. Teoria geral do Estado. 10. ed. rev. e aum. São Paulo: Malheiros, 2015. 
CANELA JUNIOR, Osvaldo. A efetivação dos direitos fundamentais através do processo coletivo: o âmbito de cognição das políticas públicas pelo Poder Judiciário. 2009. Tese (Doutorado em Direito Processual) - Faculdade de Direito, Universidade de São Paulo, São Paulo, 2009. Disponível em: <http://www.teses.usp.br/teses/disponiveis/2/2137/tde03062011-114104/pt-br.php>. Acesso em: 05 out. 2017.

CANOTILHO, J. J. Gomes. Direito constitucional e teoria da constituição. 7. ed. 15. reimp. Coimbra: Edições Almedina, 2014.

COSTA, Paulo Nogueira. O Tribunal de Contas e a boa governança. Coimbra: Coimbra Editora, 2014.

CRETELLA JÚNIOR, José. Natureza das decisões do Tribunal de Contas. Revista de Direito Administrativo, Rio de Janeiro, v. 166, p. 1-16, fev. 1986. Disponível em: <http://bibliotecadigital.fgv.br/ojs/index.php/rda/article/view/45315/43802>. Acesso em: 02 jan. 2018.

FERNANDES, Bernardo Gonçalves. Curso de direito constitucional. 9. ed. Salvador: Juspodivm, 2017.

INSTITUCIONAL. Tribunal de Contas da União. Disponível em: $<$ http://portal.tcu.gov.br/institucional/conheca-o-tcu/competencias/>. Acesso em: 08 de julho de 2017.

Tribunal de Contas do Estado do Paraná. Disponível em:

<http://www1.tce.pr.gov.br/conteudo/quem-somos/4/area/45>. Acesso em: 08 de julho de 2017.

IOCKEN, Sabrina Nunes. Avaliação de políticas públicas: instrumento de controle e garantia da qualidade do gasto público. Revista TCMRJ, Rio de Janeiro, n. 53, p. 04-09, fev. 2013. Disponível em: <http://www.tcm.rj.gov.br/Noticias/10509/REVISTA_TCMRJ_53.pdf> Acesso em: 22 jan. 2018.

LINS NETO, Jair. Tribunal de Contas: sempre combatido, nunca conhecido. Revista de Direito Administrativo, Rio de Janeiro, v. 200, p. 71-84, abr. 1995. Disponível em: <http://bibliotecadigital.fgv.br/ojs/index.php/rda/article/view/46527/46569>. Acesso em: 02 jan. 2018.

LESSA, Otávio. O controle das políticas públicas pelos tribunais de contas. Revista TCMRJ, Rio de Janeiro, n. 53, p. 10-12, fev. 2013. Disponível em: <http://www.tcm.rj.gov.br/Noticias/10509/REVISTA_TCMRJ_53.pdf>Acesso em: 22 jan. 2018.

MACHADO, Antônio Cláudio da Costa; VOLANTE, Carlos Eduardo; VIANA, Waleska Cariola. Democracia como direito fundamental de terceira geração ou dimensão. Revista ESMAT, v. 8, n. 10, p. 149-172, nov. 2016. Disponível em:

<http://esmat.tjto.jus.br/publicacoes/index.php/revista_esmat/article/view/115>. Acesso em: 
04 jan. 2017.

MELLO, Yuri Lopes de. Reserva Legal: Fundamento Constitucional e Políticas Públicas. Revista dos Tribunais Online: Doutrinas Essenciais de Direito Ambiental, São Paulo, v. 2. p. 677-700, mar. 2011. Disponível em:

$<$ http://www.revistadostribunais.com.br/maf/app/resultList/document?\&src=rl\&srguid=i0ad8 2d9a00000160339c08cc92db28c9\&docguid=I18fe29403e5f11e09ce30000855dd350\&hitguid $=\mathrm{I} 18 \mathrm{fe} 29403 \mathrm{e} 5 \mathrm{f} 11 \mathrm{e} 09 \mathrm{ce} 30000855 \mathrm{dd} 350 \& \operatorname{spos}=1 \&$ epos $=1 \& \mathrm{td}=1 \&$ context $=240 \& \mathrm{crumb}-$ action=append\&crumb-

label=Documento\&isDocFG=false \&isFromMultiSumm $=\&$ startChunk=1\&endChunk=1> . Acesso em: 4 set. 2017.

OLIVEIRA, Guilherme Fonseca de; ALVES, Fernando de Brito. Democracia e ativismo judicial: atuação contramajoritária do judiciário na efetivação dos direitos fundamentais das minorias. Argumenta Journal Law, Jacarezinho - PR, n. 20, p. 33-45, ago. 2014. ISSN 23173882. Disponível em: <http://seer.uenp.edu.br/index.php/argumenta/article/view/432>. Acesso em: 19 de setembro de 2017.

OLIVEIRA, Kátia Cristine Santos de; COSTA, Jamille Coutinho. Direito à saúde: da (in)efetividade das políticas públicas à sua judicialização como forma de garantir o mínimo existencial. Revista de Direito Brasileira. São Paulo, v. 1, p. 77-99, jul.-dez. 2011. Disponível em: <http://www.rdb.org.br/ojs/index.php/rdb/article/view/53 >. Acesso em: 27 set. 2017.

RUSSO, Thiago Nogueira; LEHFELD, Neide Aparecida de Souza. Controle jurisdicional das políticas públicas que visam concretizar o direito à saúde. Argumenta Journal Law, Jacarezinho /PR, n. 23, p. 313-331, jan. 2016. Disponível em:

<http://seer.uenp.edu.br/index.php/argumenta/article/view/628>. Acesso em: 05 out. 2017.

SILVA, José Afonso da. Curso de direito constitucional positivo. 15. ed. rev. e atual. São Paulo: Malheiros, 1998.

TACITO, Caio. Tribunais de Contas - Independência - Tribunais de Contas dos Municípios. Revista de Direito Administrativo, Rio de Janeiro, v. 242, p. 213-216, out. 2005. ISSN 22385177. Disponível em:

<http://bibliotecadigital.fgv.br/ojs/index.php/rda/article/view/42990/44605>. Acesso em: 16 jan. 2018.

TORRES, Ricardo Lobo. Curso de direito financeiro e tributário. 18. ed. Rio de Janeiro: Renovar, 2011.

A legitimidade democrática e o Tribunal de Contas. Revista de Direito Administrativo, Rio de Janeiro, v. 194, p. 31-45, abr. 1993. Disponível em: <http://bibliotecadigital.fgv.br/ojs/index.php/rda/article/view/45894>. Acesso em: 02 jan. 2018. 